\title{
Enrichment of Bread with Olive Oil Industrial By-Product
}

\author{
Annamaria Cedola ${ }^{1}$, Angela Cardinali ${ }^{2}$, Matteo Alessandro Del Nobile ${ }^{1}$ and Amalia Conte ${ }^{1}$ \\ 1. Department of Agricultural Sciences, Food and Environment, University of Foggia, Via Napoli 25 Foggia 71122, Italy \\ 2. Institute of Sciences of Food Production-CNR Via G. Amendola 122/O, Bari 70126, Italy
}

\begin{abstract}
The aim of the study was to investigate the effect of bread fortification with dry olive paste flour (DOPF), coming from Cellina di Nardò cultivar. Specifically, sensory and nutritional properties of enriched bread were investigated. In addition, the glycemic response and the bio-accessibility of polyphenols contained in the bread samples were also estimated. The addition of DOPF leads to an increase of the total phenolic compounds, total flavonoids and antioxidant activity, without compromising the final acceptability. The recovery of bio-accessible polyphenols from the simulated gastro-intestinal digestion was $59.3 \%$ for the control and $72.1 \%$ for the enriched bread. Also the glycemic response was improved in the enriched bread.
\end{abstract}

Key words: Antioxidant activity, bio-accessibility, dry olive paste flour, oil by-products, sustainable food.

\section{Abbreviations}

DOPF: dry olive paste flour;

ABTS: 2,2-azino-bis(3-ethylbenzothiazoline-6-sulfonic acid diammonium salt);

PBS: phosphate buffer saline.

\section{Introduction}

In the olive plant fruits there are a high quantity of bioactive compounds that can be recovered and used as valuable substances. From the olive oil extraction process, regardless of the method used, extraction by pressure or centrifugation, three different by-products are formed in considerable amount: olive paste, olive pomace and olive mill waste water. During olive oil processing, most of substances of high benefic effect remain in the oil wastes. So, the bioconversion of these wastes to useful products is receiving increased attention. Nevertheless, the extraction system generates a liquid/solid waste rich in hydroxytyrosol, with a concentration 10-100 fold higher than olive oil [1]. Up to now the emphasis has been focused on detoxifying these wastes prior to disposal, feeding, fertilization/composting, because they are not easily degradable by natural processes, or even used in

Corresponding author: Amalia Conte, professor, research field: food science and technology. combustion as fuel [2]. However, recovery of high value compounds or the utilization of these wastes as raw materials for new products is particularly attractive, being the recovery process of economic and practical interest. This aspect, added to the alternative proposals to diminish the environmental impact, will allow the placement of olive market in high competitive position [3]. At the epidemiological level, plant polyphenols have been suggested to reduce the risk of cardiovascular diseases, neurodegenerative disorders, cancer and diabetes [4]. Fortification with phenolics-rich ingredients is the most commonly used for improving the antioxidant potential of food and the resulting improvement of the consumer antioxidant status [5-9]. Several research groups have been worked on the alternative use of these organic residues and the recovery of valuable substances. Many of them are focused on solvent extraction with methanol, ethanol or ethyl acetate from olive pomace [10], but very scarce applications to food are recorded [11]. Among food, cereals-based products are considered the most interesting vehicle for functional supplements because in developed communities they provide more than $50 \%$ of the total energy intake [12].

Therefore, the main aim of this work was to develop a novel enriched bread with dried olive 
pomace, rich in phenolic compounds, to increase its nutritional quality and health promoting properties. Further, in order to give information about the possibility to increase the polyphenols intake through the consumption of enriched bread, the amount of total polyphenols was estimated and their total bio-accessibility, after a simulated gastro-intestinal digestion, was also assessed. Finally, in order to highlight the potential beneficial effects on health, the glycemic index modulation and the antioxidant capacity of the enriched bread were also evaluated.

\section{Materials and Methods}

\subsection{Raw Materials}

The olive paste from the Cellina di Nardò cultivar was obtained by a local olive mill (Lecce, Bari, Italy) using a Pieralisi Leopard with Multi Phases Decanter (DMP) Technology. Leopard is the two-phase decanter that can combine modern extraction technology without the addition of water. It produces a dehydrated husk similar to the one coming from a three-phase decanter; it also recovers a certain quantity of husk (olive paste) made up of wet pulp without any traces of kernel.

The olive paste was dried in a dryer (SG600, Namad, Rome, Italy) at $35{ }^{\circ} \mathrm{C}$ for $48 \mathrm{~h}$ to reach a moisture of $7.18 \pm 0.61$ and then reduced to a fine powder by a hammer mill (16/BV-Beccaria s.r.l., Cuneo, Italy) to obtain the olive paste flour $(\leq 500$ $\mu \mathrm{m})$. Wheat flour (WF) for bread production was supplied from Agostini mill (Montefiore dell'Aso, Ascoli Piceno, Italy). Fresh compressed yeast, cream of tartar, sodium bicarbonate, sugar and salt were purchased from a local market. All solvents and the enzymes used for the in vitro digestion were obtained from Sigma-Aldrich (Milan, Italy).

\subsection{Bread-Making Process}

Bread dough mixing, processing and baking were carried out with laboratory-scale equipment as described by Saccotelli et al. [13]. The DOPF was added to the dough at $10 \%(\mathrm{w} / \mathrm{w})$. The control sample (bread without DOPF, B-CTRL) was obtained with a pre-mixture of $1,500 \mathrm{~g}$ of $\mathrm{WF}$ and $900 \mathrm{~g}$ of water stirred at high speed for $10 \mathrm{~min}$ in a mixer (Conti, Bussolengo, Verona, Italy). Once a homogeneous mixture was obtained, $45 \mathrm{~g}$ of compressed fresh yeast, $15 \mathrm{~g}$ of sugar and $30 \mathrm{~g}$ of salt were added and it was mixed at the average speed for $15 \mathrm{~min}$. After complete mixing, the dough rested in bulk in the incubator (Thermogel, Varese, Italy) at constant temperature $\left(30{ }^{\circ} \mathrm{C}\right.$ ) and relative humidity $(85 \%)$ for $60 \mathrm{~min}$. Subsequently, dough portions of about $800 \mathrm{~g}$ were manually rounded and placed above a baking tray in the incubator at the same conditions reported above, for the final fermentation, lasting $30 \mathrm{~min}$. After the fermentation process, the samples were baked in an electric oven (Europa Forni, Vicenza, Italy) at $230{ }^{\circ} \mathrm{C}$ for $15 \mathrm{~min}$, followed by $35 \mathrm{~min}$ at $200{ }^{\circ} \mathrm{C}$. The enriched experimental sample (bread with DOPF, $\mathrm{B}-\mathrm{DOPF}$ ) was prepared using the same procedure as for the B-CTRL sample, with dry olive paste (150 g), in partial substitution of $\mathrm{WF}$, and in addition to compressed fresh yeast sodium bicarbonate $(18 \mathrm{~g})$ and cream of $\operatorname{tartar}(36 \mathrm{~g})$ were also added. The DOPF was pre-treated with milk as described by Cedola et al. [11]. Bread samples were produced three times.

\subsection{Sensory Analysis}

Bread samples were submitted to a panel of six trained tasters (women, aged between 25 and 48) in order to evaluate the bread sensory attributes. The panelists had at least several years of experience in sensory evaluation prior to this study; however, they were retrained for this study in a session of $2 \mathrm{~h}$ to be experienced in the product and terminology. Before sensory analysis, samples were sliced with an electric slicing knife (thickness of $15 \mathrm{~mm}$ ) (Atlantic; Calenzano, Firenze, Italy) without removing the crust. The bread samples were evaluated on a 9-point scale anchored where 1 corresponded to extremely unpleasant, 9 to extremely pleasant and 5 to the 
threshold acceptability. In particular, seven attributes were considered for the bread acceptance: color, odor, taste, crust and crumb firmness, presence of large bubbles and overall quality.

\subsection{Total Phenolic Compounds, Total Flavonoids and ABTS Antioxidant Activity}

To determine total phenols, flavonoids and ABTS antioxidant activity, the extraction was performed as described by Biney et al. [14] with slight modifications. Bread samples, without crust, were dried with a ventilated stove (BINDER $\mathrm{GmbH}$, Tuttlingen, Germany) at $35{ }^{\circ} \mathrm{C}$ and milled to obtain a powder. One gram $(1 \mathrm{~g})$ of dried sample was mixed with $10 \mathrm{~mL}$ of acidified methanol $\left(\mathrm{HCl} / \mathrm{H}_{2} \mathrm{O}: \mathrm{MeOH}\right.$, 20:80). The mixtures were included in $50 \mathrm{~mL}$ centrifuge tubes and shaken at room temperature in darkness for $2 \mathrm{~h}$ at $300 \mathrm{rpm}$ using orbital shaker (HS 260 BASIC, IKA, Staufen, Germany). Next, the samples were centrifuged at $5{ }^{\circ} \mathrm{C}$ for $15 \mathrm{~min}$ at 10,000 rpm (5804R, Eppendorf, Milan, Italy) and supernatant was collected and filtered (polytetrafluoroethylene (PTFE) $0.45 \mu \mathrm{m}$ ) prior to the analytical determinations. Triplicate extractions were made for each sample.

Total phenolic compounds were determined at 740 $\mathrm{nm}$ by UV-vis spectrophotometry (UV1800, Shimadzu Italia s.r.l., Milan, Italy) according to Folin-Ciocalteu method [15]. Specifically, $0.5 \mathrm{~mL}$ of sample was mixed with $2.5 \mathrm{~mL}$ of Folin-Ciocalteu reagent and, after $5 \mathrm{~min}, 2 \mathrm{~mL}$ of $\mathrm{NaCO}_{3}(75 \mathrm{~g} / \mathrm{L})$ was added. The sample was kept in darkness at room temperature for $2 \mathrm{~h}$. The total phenols were expressed as milligram of gallic acid equivalents (GAE) per gram of dry weight (dw), according to a calibration curve $\left(3.12-100 \mathrm{mg} / \mathrm{L} ; R^{2}=0.9989\right)$.

Total flavonoids content was determined by aluminum chloride colorimetric method, according to Chiung-Tsu et al. [16]. Samples $(0.5 \mathrm{~mL})$ were mixed with $2 \mathrm{~mL}$ of distilled water and $150 \mu \mathrm{L}$ of a $5 \%$ sodium nitrite $\left(\mathrm{NaNO}_{2}\right)$ solution. After $6 \mathrm{~min}, 150 \mu \mathrm{L}$ of a $10 \%$ aluminum chloride $\left(\mathrm{AlCl}_{3}\right)$ solution was added and the mixture was allowed to stand for $6 \mathrm{~min}$. Finally, $1 \mathrm{~mL}$ of $1 \mathrm{~mol} / \mathrm{L}$ sodium hydroxide $(\mathrm{NaOH})$ was added until the volume was made up to $5 \mathrm{~mL}$ with distilled water. The final mixture was filtered through a $0.45 \mu \mathrm{m}$ nylon filter and measured at $415 \mathrm{~nm}$ with a spectrophotometer (UV1800; Shimadzu Italia s.r.l). The total flavonoids were expressed in milligram of quercetin equivalent (QE) per gram of dw. Quercetin standard solutions were used for constructing the calibration curve $\left(12.5-200 \mathrm{mg} / \mathrm{L} ; R^{2}=0.9986\right)$. The antioxidant activity was evaluated at $728 \mathrm{~nm}$ by UV-vis spectrophotometry (UV1800, Shimadzu Italia s.r.l., Milan, Italy) using the ABTS assay according to the method of Re et al. [17]. To the aim, ABTS stock solution $(7 \mathrm{mmol} / \mathrm{L})$ and potassium persulfate $(140$ $\mathrm{mmol} / \mathrm{L}$ ) were utilized. The ABTS radical cation $(\mathrm{ABTS} \cdot+)$ was obtained by reacting ABTS stock solution with $2.45 \mathrm{mmol} / \mathrm{L}$ potassium persulfate and leaving the mixture in the dark at room temperature for 12-16 h. The ABTS++ solution was diluted to an absorbance of $0.700 \pm 0.020$ at $728 \mathrm{~nm}$, with 5 $\mathrm{mmol} / \mathrm{L}$ phosphate buffered saline $(\mathrm{pH} 7.4)$. Then, $300 \mu \mathrm{L}$ of sample extract was added to $2.2 \mathrm{~mL}$ of ABTS-+ diluted solution and after $6 \mathrm{~min}$ at room temperature the mixture was measured. A calibration curve was built using Trolox as standard, at concentrations between $1.56 \mathrm{mg} / \mathrm{L}$ and $50 \mathrm{mg} / \mathrm{L}\left(R^{2}=\right.$ 0.9988 ) and the antioxidant activity was expressed as milligram Trolox equivalents for gram of $\mathrm{dw}$.

\subsection{Glycemic Index}

Digestion was carried out as described by Padalino et al. [18] with some modifications. Briefly, bread samples without crust (5 g) were chopped and tipped into a digestion vessel with $50 \mathrm{~mL}$ of distilled water and $5 \mathrm{~mL}$ maleate buffer $(0.2 \mathrm{M} \mathrm{pH} 6.0$, containing $0.1 \mathrm{~g}$ sodium azide and $0.15 \mathrm{~g} \mathrm{CaCl}_{2}$ per liter) in an block at $37{ }^{\circ} \mathrm{C}$ (GFL 1092; GFL Gesellschaft für Labortechnik, Burgwedel, Germany) and allowed to balance for $15 \mathrm{~min}$. The other phases were performed 
following the above-reported method [18] without any modifications. The results were plotted as glucose release $(\mathrm{mg})$ per $\mathrm{g}$ of sample vs. time. The glycemic index was calculated as the incremental area under the curve (iAUC) for the tested products divided by the iAUC of a reference food (white bread) [19].

\subsection{Polyphenol Bio-accessibility by in Vitro Digestion}

Polyphenol bio-accessibility from enriched bread was determined using a three-stage simulated digestion including oral, gastric and small intestinal phase, as described by D'Antuono et al. [20] with slight modifications. The oral phase solution $(6 \mathrm{~mL})$, containing 5\% mucin (M2378; Sigma Aldrich), 3\% uric acid (U2625; Sigma Aldrich), 40\% urea (U5378; Sigma Aldrich) of sample and $10.6 \mathrm{~g}$ of $\alpha$-amylase (A3176; Sigma Aldrich), was added to the previously chopped bread without crust $(1 \mathrm{~g})$. The reaction tube was mixed and incubated in a covered shaking water bath at the temperature of $37^{\circ} \mathrm{C}$, the speed of $85 \mathrm{rpm}$ and for a time of $10 \mathrm{~min}$. Samples were then diluted to $30 \mathrm{~mL}$ with saline solution $(0.9 \% \mathrm{NaCl})$. The last two phases (gastric and small intestinal) were performed following the above-reported method [20] without any modifications. At the end of the small intestinal phase, an aliquot $(3 \mathrm{~mL})$ representing the crude digested $(\mathrm{CD})$ was collected and the samples were centrifuged at $10,000 \times \mathrm{g}$ for $1 \mathrm{~h}$ at $4{ }^{\circ} \mathrm{C}$ to separate the aqueous intestinal digested (AQ) from the residual solid. Aliquots of $\mathrm{AQ}$, for both control and enriched bread, were collected, filtered using a $0.2 \mu \mathrm{m}$ PTFE filter and analyzed with Folin-Ciocalteu spectrophotometric (UV1800, Shimadzu Italia s.r.l., Milan, Italy) method at $740 \mathrm{~nm}$. The bio-accessibility of phenols was expressed as the bio-accessibility percentage using the following expression:
Bio-accessibiliy $(\%)=(C F / C I) \times 100$

where $\mathrm{CF}$ is the final concentration of total polyphenols in the aqueous intestinal digesta and $\mathrm{CI}$ is the initial total polyphenols concentration in the undigested bread.

\subsection{Statistical Analysis}

Experimental data were compared by a one-way analysis of variance (ANOVA). Duncan's multiple range test, with the option of homogeneous groups ( $p$ $<0.05)$, was carried out to determine significant differences among bread samples. STATISTICA 7.1 for Windows (Stat Soft, Inc., Tulsa, OK, USA) was used.

\section{Results and Discussion}

The impact of olive oil by-products on both sensory and nutritional quality of bread was evaluated. Afterward the enriched bread was subjected to in vitro digestion to evaluate the glycemic response, then the bio-accessibility of polyphenols available for intestinal absorption was also evaluated.

\subsection{Sensory and Chemical Characteristics}

The results of sensory test are listed in Table 1 for bread with and without olive oil by-products. It is well known that olive oil contains tyrosol and oleuropein, phenols with very bitter and spicy taste [21]. For this reason the addition of olive oil by-products to food is expected to affect the sensory quality. Results of the study demonstrate that in general, the enriched bread recorded acceptable score, much higher than the sensory threshold. Some differences compared to the control were highlighted in terms of color, due to the purplish color of the olive oil by-products, and in terms of taste, due to the high content of polyphenols.

Table 1 Sensory characteristics of bread samples.

\begin{tabular}{llllllll}
\hline Sample & Color & Odor & Taste & Crust firmness & Crumb firmness & Large bubbles & Overall quality \\
\hline B-CTRL & $8.00 \pm 0.00^{\mathrm{a}}$ & $8.00 \pm 0.00^{\mathrm{a}}$ & $7.75 \pm 0.29^{\mathrm{a}}$ & $7.50 \pm 0.00^{\mathrm{a}}$ & $7.50 \pm 0.00^{\mathrm{a}}$ & $7.00 \pm 0.00^{\mathrm{a}}$ & $7.75 \pm 0.27^{\mathrm{a}}$ \\
B-DOPF & $6.55 \pm 0.27^{\mathrm{b}}$ & $7.75 \pm 0.27^{\mathrm{a}}$ & $6.75 \pm 0.27^{\mathrm{b}}$ & $7.50 \pm 0.00^{\mathrm{a}}$ & $7.50 \pm 0.00^{\mathrm{a}}$ & $6.68 \pm 0.24^{\mathrm{b}}$ & $7.00 \pm 0.32^{\mathrm{b}}$ \\
\hline
\end{tabular}

B-CTRL: bread without DOPF; B-DOPF: bread with DOPF.

${ }^{\mathrm{a}, \mathrm{b}}$ Data in columns with different superscripts are significantly different $(p<0.05)$. 
The addition of DOPF also slightly interfered with the network formation, thus influencing the final bread bubbles that were considered more acceptable in the control samples than in the enriched bread. The literature [22] also confirms that other ingredients added to the main raw materials for bread enrichment generally modify the network formation and destabilize the gas cells, thus causing low gas retention. Saccotelli et al. [23] also observed that adding bran to bread formulation compromised the retention of gas and the final loaf volume. However, in the current study, the addition of chemical leavening agents greatly improved the formation of gas in the dough, thus maintaining an acceptable quality. Odor, crust and crumb firmness remained similar in both control and fortified bread.

The total phenolic compounds (mg GAE/g dw), flavonoids (mg QE/g dw) and antioxidant activity ( $\mathrm{mg}$ Trolox equivalent/g dw), measured by ABTS assay are shown in Table 2. The obtained results indicate that the dry olive paste has high phenols content, equal to $45.09 \mathrm{mg} \mathrm{GAE} / \mathrm{g} \mathrm{dw}$, capable to improve the nutritional quality of enriched food, as also found in other applications of oil by-products [11]. Specifically, the content of total phenols in the experimental samples, showed in Table 3, varied from $0.28 \mathrm{mg}$ $\mathrm{GAE} / \mathrm{g} \mathrm{dw}$ in the B-CTRL sample to $1.96 \mathrm{mg} \mathrm{GAE} / \mathrm{g}$ $\mathrm{dw}$ in the enriched bread, that means seven fold increase. Flavonoids, that constitute the largest group of plant phenolic compounds [24], are present in high amounts in dry olive paste (36.11 mg QE/g dw). Therefore, the addition of DOPF to bread significantly increased also the flavonoid content which varied from $0.06 \mathrm{mg} \mathrm{QE} / \mathrm{g} \mathrm{dw}$ in the B-CTRL sample to 0.85 $\mathrm{mg} \mathrm{QE} / \mathrm{g} \mathrm{dw}$ in the enriched bread. As reported by others authors [25] the olive paste is very rich in flavonoid compounds and among them, luteolin and quercetin aglycons are the most abundant. As a consequence of the enrichment by bioactive compounds from oil by-products, a significant antioxidant capacity was also found in the fortified bread, compared to the control sample (1.12 against $0.02 \mathrm{mg}$ Trolox equivalent/g bread). The total phenols are considered the main responsible for antioxidant activity; several studies have been carried out to correlate phenolic composition of by-products with their antioxidant properties [26, 27].

\subsection{Glycemic Index}

The glycemic index is a ranking parameter for carbohydrate-containing foods, varying from 0 to 100 , based on the ratio of the area under the curve (0-180 min), compared to a reference (white wheat bread). Fig. 1 highlights that bread sample manufactured with olive paste recorded a significant lower glycemic index value compared to the B-CTRL sample, most probably because the olive paste enriched bread is rich in fibers. Numerous studies have focused on determining the dietary fiber content of olive fruits and their by-products, thus identifying pectins (arabinans, homogalacturonans and rhamnogalacturonans), cellulose, hemicelluloses and lignin. Scientific literature [28] also confirms that addition of dietary fibers to food very rich in carbohydrates as bread and pasta can reduce the in vitro glycemic response. In addition, also the increased amount of polyphenols can contribute to the modulation of glucose absorption. In particular, in the B-DOPF is present, with high probability, the cyaniding-3-glucoside, the anthocyanin which gives the

Table 2 Total phenols, total flavonoids and antioxidant activity of wheat flour (WF) and DOPF.

\begin{tabular}{llll}
\hline Sample & $\begin{array}{l}\text { Total phenols } \\
(\mathrm{mg} \mathrm{GAE} / \mathrm{g} \mathrm{dw}) \pm \mathrm{SD}\end{array}$ & $\begin{array}{l}\text { Total flavonoids } \\
(\mathrm{mg} \text { QE/g dw }) \pm \mathrm{SD}\end{array}$ & $\begin{array}{l}\text { Antioxidant activity } \\
(\mathrm{mg} \text { Trolox equivalent } / \mathrm{g} \mathrm{dw}) \pm \mathrm{SD}\end{array}$ \\
\hline WF & $0.29 \pm 0.01^{\mathrm{a}}$ & $0.11 \pm 0.02^{\mathrm{a}}$ & $0.24 \pm 0.02^{\mathrm{a}}$ \\
DOPF & $45.09 \pm 0.91^{\mathrm{b}}$ & $36.11 \pm 0.71^{\mathrm{b}}$ & $21.64 \pm 0.38^{\mathrm{b}}$ \\
\hline
\end{tabular}

GAE: gallic acid equivalents; QE: quercetin equivalent.

${ }^{\mathrm{a}, \mathrm{b}}$ Data in columns with different superscripts are significantly different $(p<0.05)$. 


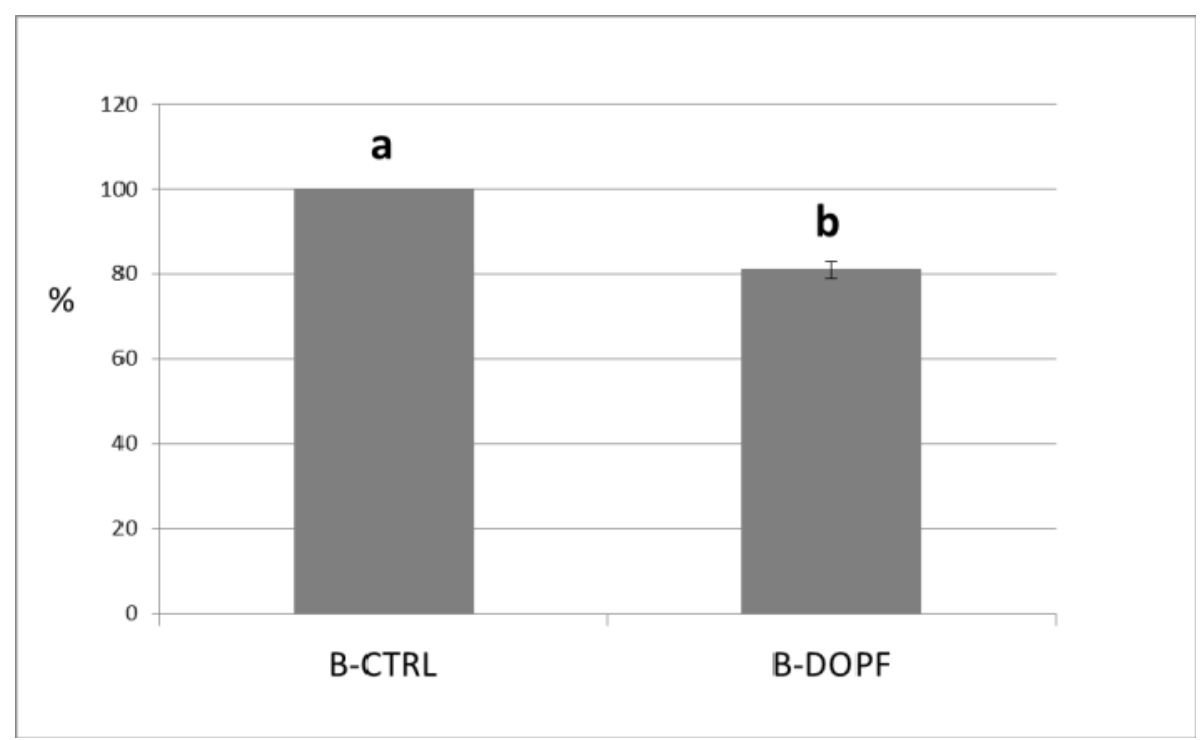

Fig. 1 Glycemic index of bread with and without dry olive paste addition.

B-CTRL: bread without DOPF; B-DOPF: bread with DOPF.

The different letters show significant difference among means of triplicate determinations $(p<0.05)$.

characteristic purple color to the cultivar Cellina di Nardò [29]. This compound has an important effect on the glucose absorption modulation as reported by some authors on the anthocyanic component of blueberry and pomegranate using a Caco-2TC7cells/biosensors telemetric device [30]. The results reported by these authors were in agreement with the in vivo hypoglycemic effect reported by McDougal and Stewart [31], thus confirming the inhibitory effect of anthocyanins on alpha-glucosidase activity. Moreover other authors compared the hypoglycemic activity of an anthocyanin-enriched fraction with respect to blueberry polyphenols extract, ascribing to the anthocyanins the hypoglycemic activity of blueberry [32].

\subsection{Polyphenol Bio-accessibility}

Fig. 2 reports the percentage of bio-accessibility of total polyphenols after the in vitro digestion process. The bio-accessibility represents the polyphenolic fraction stable to the gastro-intestinal conditions and potentially available for the intestinal absorption. From Fig. 2, it is noteworthy to underline that the total polyphenols of the enriched bread are stable under gastric and small-intestinal digestive conditions with respect to the small phenolic components of the control, thus highlighting the bio-accessibility of olive oil by-products compounds. This high stability could be also confirmed by the presence of milk proteins used in the production of enriched bread as was discussed by Lamothe et al. [33] on green tea extract. These authors found that the addition of green tea extract to dairy matrices promoted the formation of polyphenol-protein complexes, which significantly improved the polyphenol stability in simulated gastro-intestinal environment and consequently enhanced the antioxidant activity. Several authors have also discussed the influence of the food matrix in the digestion process, highlighting as the food can control the release of bioactive compounds in the gastro-intestinal environment [34]. As a matter of fact, when verbascoside and isoverbascoside, both polyphenols present in olive mill wastewater, were digested as extracts, their bio-accessibility values were lower than when the matrix (table olive) was present $[20,35]$. The bio-accessibility of the main polyphenols present in olives was already investigated. A study performed on table olives cv Bella di Cerignola described the high stability of different 


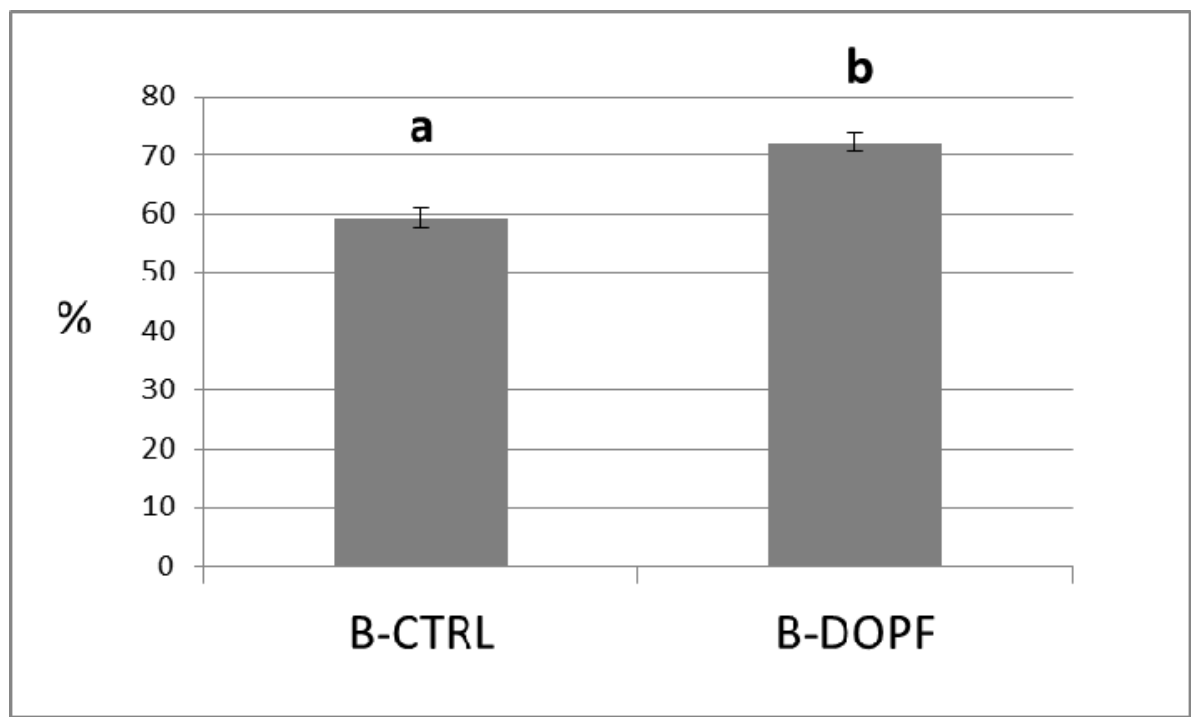

Fig. 2 Bio-accessibility of polyphenols of bread with and without dry olive paste addition.

B-CTRL: bread without DOPF; B-DOPF: bread with DOPF.

Data represent mean \pm standard error of mean for $n=3$ digestion experiments. The different letters show significant difference among means of triplicate determinations $(p<0.05)$.

Table 3 Total phenols, total flavonoids and antioxidant activity of bread with and without DOPF.

\begin{tabular}{llll}
\hline Sample & $\begin{array}{l}\text { Total phenols } \\
(\mathrm{mg} \mathrm{GAE} / \mathrm{g} \mathrm{dw}) \pm \mathrm{SD}\end{array}$ & $\begin{array}{l}\text { Total flavonoids } \\
(\mathrm{mg} \mathrm{QE} / \mathrm{g} \mathrm{dw}) \pm \mathrm{SD}\end{array}$ & $\begin{array}{l}\text { Antioxidant activity } \\
(\mathrm{mg} \text { Trolox equivalent } / \mathrm{g} \mathrm{dw}) \pm \mathrm{SD}\end{array}$ \\
\hline B-CTRL & $0.28 \pm 0.01^{\mathrm{a}}$ & $0.06 \pm 0.01^{\mathrm{a}}$ & $0.02 \pm 0.01^{\mathrm{a}}$ \\
B-DOPF & $1.96 \pm 0.04^{\mathrm{b}}$ & $0.85 \pm 0.03^{\mathrm{b}}$ & $1.12 \pm 0.02^{\mathrm{b}}$ \\
\hline
\end{tabular}

B-CTRL: bread without DOPF; B-DOPF: bread with DOPF. GAE: gallic acid equivalents; QE: quercetin equivalent.

${ }^{\mathrm{a}, \mathrm{b}}$ Data in columns with different superscripts are significantly different $(p<0.05)$.

identified polyphenol classes [20]. The authors showed a percentage of bio-accessibility ranging from $7 \%$ of the flavonoid luteolin to $99 \%$ of tyrosol. Also the phenolic characterization of the olive cultivar Cellina di Nardò was recently studied [36, 37]. The authors reported that the cultivar, together with the main phenolic compounds characteristic of the olive matrix, such as hydroxytyrosol, tyrosol, verbascoside and luteolin, showed the peculiar presence of cyanidin-3-glucoside and cyanidin-3-rutinoside, both compounds responsible for the red/purple color of the olive pulp. Besides, among the identified polyphenols, hydroxytyrosol and tyrosol were the most bio-accessible $\quad(\sim 90 \%$ for both $)$ instead cyanidin-3-glucoside showed a lower bio-accessibility level (almost 40\%) [36].

To sum up, the great polyphenols stability recorded in the enriched samples studied in this paper permits to speculate about the possibility to increase the polyphenols intake through the consumption of supplemented bread. Studies are in progress in order to elucidate the polyphenolic composition of the enriched matrix to the aim to understand which specific compound present in the matrix could produce significant biological effects.

\section{Conclusions}

In this study the impact of olive oil by-products on both sensory and nutritional characteristics of bread was evaluated. In addition, the glycemic response and the bio-accessibility of polyphenols of bread samples were also estimated. The bread fortified with $10 \%$ of olive paste recorded high content of phenols and flavonoids and, consequently exhibiting a higher antioxidant activity than the control sample. The phenolic content of olive paste was found stable under 
digestive conditions, so the enriched bread reduced the glycemic index. The in vitro digestion model also confirmed that the phenols are bio-accessible components. From the sensory point of view the fortified bread was acceptable. Therefore, it is possible to conclude that the fortification of DOPF considerably improved the nutritional quality, without compromising the product acceptability. Slight differences between control and enriched bread were found in terms of taste and color but in general enriched bread remained acceptable.

\section{References}

[1] Lesage-Meessen, L., Navarro, D., Maunier, S., Sigoillot, J. C., Lorquin, J., Delattre, M., Simon, J. L., Asther, M., and Labat, M. 2001. "Simple Phenolic Content in Olive Oil Residues as a Function of Extraction Systems.” Food Chem. 75 (4): 501-7.

[2] Vlyssides, A. G., Loizides, M., and Karlis, P. K. 2004. "Integrated Strategic Approach for Reusing Olive Oil Extraction.” J. Clean. Prod. 12 (6): 603-11.

[3] Niaounakis, M., and Halvadakis, P. 2004. Olive-Mill Waste Management: Literature Review and Patent Survey. Athens: Typothito-George Dardanos Publications, 34-7.

[4] Arts, I. C., and Hollman, P. C. 2005. "Polyphenols and Disease Risk in Epidemiologic Studies." Am. J. Clin. Nutr. 81 (1 Suppl): 317-25.

[5] Chlopicka, J., Pasko, P., Gorinstein, S., Jedryas, A., and Zagrodzki, P. 2012. "Total Phenolic and Total Flavonoid Content, Antioxidant Activity and Sensory Evaluation of Pseudocereal Breads.” LWT-Food Sci. Technol. 46 (2): 548-55.

[6] Fan, L., Zhang, S., Yu, L., and Ma, L. 2006. "Evaluation of Antioxidant Property and Quality of Breads Containing Auricularia auricula Polysaccharide Flour." Food Chem. 101 (1): 1158-63.

[7] Gawlik-Dziki, U., Dziki, D., Baraniak, B., and Lin, R. 2009. "The Effect of Simulated Digestion in Vitro on Bioactivity of Wheat Bread with Tartary Buckwheat Flavones Addition.” LWT-Food Sci. Technol. 42 (1): $137-43$

[8] Gawlik-Dziki, U., Swieca, M., Dziki, D., Baraniak, B., Tomiło, J., and Czyz, J. 2013. "Quality and Antioxidant Properties of Breads Enriched with Dry Onion (Allium cepa L.) Skin." Food Chem. 138 (2-3): 1621-8.

[9] Lim, H. S., Park, S. H., Ghafoor, K., Hwang, S. Y., and Park, J. 2011. "Quality and Antioxidant Property of Bread Containing Turmeric (Curcuma longa L.)
Cultivated in South Korea." Food Chem. 112 (4): 1577-82.

[10] Fernández-Bolaños, J., Rodríguez, G., Rodríguez, R., Guillén, R., and Jiménez, A. 2006. "Extraction of Interesting Organic Compounds from Olive Oil Waste." Grasas Aceites 57 (1): 95-106.

[11] Cedola, A., Cardinali, A., Del Nobile, M. A., and Conte, A. 2017. "Fish Burger Enriched by Olive Oil Industrial By-Product." Food Sci. Nutr. 5 (4): 837-44.

[12] Akhtar, S., Anjum, F. M., and Anjum, M. A. 2011. "Micronutrient Fortification of Wheat Flour: Recent Development and Strategies." Food Res. Int. 44 (3): 652-9.

[13] Saccotelli, M. A., Conte, A., Burrafato, K. R., Calligaris, S., Manzocco, L., and Del Nobile, M. A. 2017. "Optimization of Durum Wheat Bread Enriched with Bran.” Food Sci. Nutr. 5 (3): 689-95.

[14] Biney, K., and Beta, T. 2014. "Phenolic Profile and Carbohydrate Digestibility of Durum Spaghetti Enriched with Buckwheat Flour and Bran." LWT-Food Sci. Technol. 57 (1): 569-79.

[15] Spinelli, S., Conte, A., Lecce, L., Incoronato, A. L., and Del Nobile, M. A. 2015. "Microencapsulated Propolis to Enhance the Antioxidant Properties of Fresh Fish Burgers." J. Food Process Eng. 38 (6): 527-35.

[16] Chiung-Tsu, K., Tzu-Hao, L., Tai-Hao, H., Frang-Yi, L., and Hui-Yin, C. 2015. "Antioxidant and Antiglycation Properties of Different Solvent Extracts from Chinese Olive (Canarium album L.) Fruit." Asian Pac. J. Trop. Med. 8 (12): 1013-21.

[17] Re, R., Pellegrini, N., Proteggente, A., Pannala, A., Yang, M., and Rice-Evans, C. 1999. "Antioxidant Activity Applying an Improved ABTS Radical Cation Decolorization Assay." Free Radic. Biol. Med. 26 (9-10): 1231-7.

[18] Padalino, L., Conte, A., Lecce, L., Dikyova, D., and Sicari, V. 2015. "Durum Wheat Whole-Meal Spaghetti with Tomato Peel: How By-Products Particles Size Can Affect Final Quality of Pasta." J. Food Process Technol. 6 (1): 500-23.

[19] Chillo, S., Ranawana, D. V., and Henry, C. J. K. 2011. "Effect of Two Barley $\beta$-Glucan Concentrates on in Vitro Glycaemic Impact and Cooking Quality of Spaghetti." LWT-Food Sci. Technol. 44 (4): 940-8.

[20] D'Antuono, I., Garbetta, A., Ciasca, B., Linsalata, V., Minervini, F., Lattanzio, V. M. T., Logrieco, A. F., and Cardinali, A. 2016. "Biophenols from Table Olive cv Bella di Cerignola: Chemical Characterization, Bioaccessibility, and Intestinal Absorption.” J. Agric. Food Chem. 64 (28): 5671-8.

[21] Cardinali, A., Cicco, N., Linsalata, V., Minervini, F., Pati, S., Pieralice, M., Tursi, N., and Lattanzio, V. 2010. 
"Biological Activity of High Molecular Weight Phenolics from Olive Mill Wastewate." J. Agric. Food Chem. 58 (15): 8585-90.

[22] Hemdane, S., Leys, S., Jacobs, P. J., Dornez, E., Delcour, J. A., and Courtin, C. M. 2015. "Wheat Milling By-Products and Their Impact on Bread Making." Food Chemistry 187 (15): 280-9.

[23] Saccotelli, M. A., Conte, A., Burrafato, K. R., Calligaris, S., Manzocco, L., and Del Nobile, M. A. 2017. "Optimization of Durum Wheat Bread Enriched with Bran." Food Science \& Nutrition 5 (3): 689-95.

[24] Harborne, J. B., Baxter, H., and Moss, G. P. 1999. Phytochemical Dictionary: A Handbook of Bioactive Compounds from Plants. London: Taylor \& Francis, 56-9.

[25] Padalino, L., D’Antuono, I., Durante, M., Conte, A., Cardinali, A., Linsalata, V., Mita, G., Logrieco, A. F., and Del Nobile, M. A. 2018. "Use of Olive Oil Industrial By-Product for Pasta Enrichment.” Antioxidants 7 (4): 59.

[26] Gregoris, E., and Stevanato, R. 2010. "Correlations between Polyphenolic Composition and Antioxidant Activity of Venetian Propolis.” Food Chem. Toxico. 48 (1): 76-82.

[27] Gawlik-Dziki, U., Dziki, D., Swieca, M., Lukasz, S., Rozylo, R., and Szymanowska, U. 2015. "Bread Enriched with Chenopodium quinoa Leaves Powder-The Procedures for Assessing the Fortification Efficiency." Food Sci. Technol. 62 (2): 1226-34.

[28] Fernández-Bolaños, J., Rodríguez, G., Rodríguez, R., Guillén, R., and Jiménez, A. 2006. "Extraction of Interesting Organic Compounds from Olive Oil Waste." Grasas y Aceites 57 (1): 95-106.

[29] Vosloo, M. C. 2005. "Some Factors Affecting the Digestion of Glycemic Carbohydrates and the Blood Glucose Response.” J. Fam. Ecol. Consum. Sci. 33 (8): 1-9.

[30] Barberis, A., Garbetta, A., Cardinali, A., Bazzu, G., D’Antuono, I., Rocchitta, G., Fadda, A., Linsalata, V., D'Hallewin, G., Serra, P. A., and Minervini, F. 2017.
"Real-Time Monitoring of Glucose and Phenols Intestinal Absorption through an Integrated Caco-2TC7Cells/Biosensore Telemetric Device: Hypoglycemic Effect of Fruit Phytochemicals." Biosens Bioelectron. 88 (5): 159-66.

[31] McDougall, G. J., and Stewart, D. 2005. "The Inhibitory Effects of Berry Polyphenols on Digestive Enzymes." Biofactors 23: 189-95.

[32] Grace, M. H., Ribnicky, D. M., Kuhn, P., Poulev, A., Logendra, S., Yousef, G. G., Raskin, I., and Lila, M. A. 2009. "Hypoglycemic Activity of a Novel Anthocyanin-Rich Formulation from Low Bush Blueberry, Vaccinium angustifolium Aiton." Phytomedicine 16 (5): 406-15.

[33] Lamothe, S., Azimy, N., Bazinet, L., Couillard, C., and Britten, M. 2014. "Interaction of Green Tea Polyphenols with Dairy Matrices in a Simulated Gastrointestinal Environment." Food Funct. 5 (10): 2621-31.

[34] D’Archivio, M., Filesi, C., Varì, R., Scazzocchio, B., and Masella, R. 2010. "Bioavaialability of the Polyphenols: Status and Controversies." Int. J. Mol. Sci. 11 (4): 1321-42.

[35] Cardinali, A., Linsalata, V., Lattanzio, V., and Ferruzzi, G. M. 2011. "Verbascosides from Olive Mill Waste Water: Assessment of Their Bioaccessibility and Intestinal Uptake Using an in Vitro Digestion/Caco-2 Model System.” J. Food Sci. 76 (2): 48-54.

[36] D'Antuono, I., Bruno, A., Linsalata, V., Minervini, F., Garbetta, A., Tufariello, M., Mita, G., Logrieco, A. F., Bleve, G., and Cardinali, A. 2018. "Fermented Apulian Table Olives: Effect of Selected Microbial Starters on Polyphenols Composition, Antioxidant Activities and Bioaccessibility." Food Chem. 248 (15): 137-45.

[37] Durante, M., Tufariello, M., Tommasi, L., Lenucci, M. S., Bleve, G., and Mita, G. 2018. "Evaluation of Bioactive Compounds in Black Table Olives Fermented with Selected Microbial Starters.” J. Sci. Food Agric. 98 (1): 96-103. 